\title{
Targeted Radiotherapy of the Tumor Cavity after Surgical Resection of Aggressive Recurrent Brain Metastasis: A Case Report
}

\author{
Pavel Fadrus $^{a}$ Tomas Kazda $^{b, c}$ Petr Dvoracek ${ }^{b}$ Petr Pospisil $^{b, c}$ \\ Ludmila Hynkovab, $c$ Jana Zitterbartovab, $c$ Radana Dymackovab, $c$ \\ Ivana Kolouskovad Renata Belanovad, e Tomas Prochazkab, c \\ Pavel Slampab,c \\ aDepartment of Neurosurgery, University Hospital Brno and Faculty of Medicine, Masaryk \\ University, Brno, Czech Republic; bepartment of Radiation Oncology, Masaryk Memorial \\ Cancer Institute, Brno, Czech Republic; 'Department of Radiation Oncology, Faculty \\ of Medicine, Masaryk University, Brno, Czech Republic; ${ }^{\mathrm{d}}$ Faculty of Medicine, Masaryk

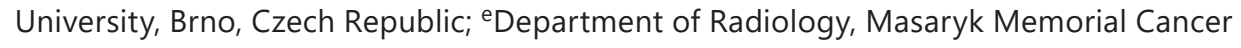 \\ Institute, Brno, Czech Republic
}

\section{Keywords}

Brain metastases · Radiotherapy $\cdot$ Local control

\section{Abstract}

Postoperative management of patients with brain metastases is controversial. Besides local control, cognitive function and quality of life are the most important outcomes of postoperative radiotherapy. In this case report, we introduce a patient with aggressive recurred solid metastasis treated with repeated surgery and an individual radiotherapy approach in order to highlight that close mutual collaboration leads to a clear benefit for our patients. The local targeted radiotherapy with 35 Gy in 10 fractions was performed with the volumetric modulated arc technique, leading to more than 2.5 years of local control and survival without any of the side effects usually attributed to whole brain radiotherapy.

\section{Introduction}

Brain metastases represent a serious complication that rapidly worsens the prognosis of all cancer patients with this type of dissemination [1]. The therapeutic options are limited; an unselected cohort of 121 patients irradiated at our hospital in 2011 had a median overall survival of only 3.1 months [2]. Prolonged survival is expected with personalized precise oncological treatment with the identification of new potential targets for targeted therapy or 


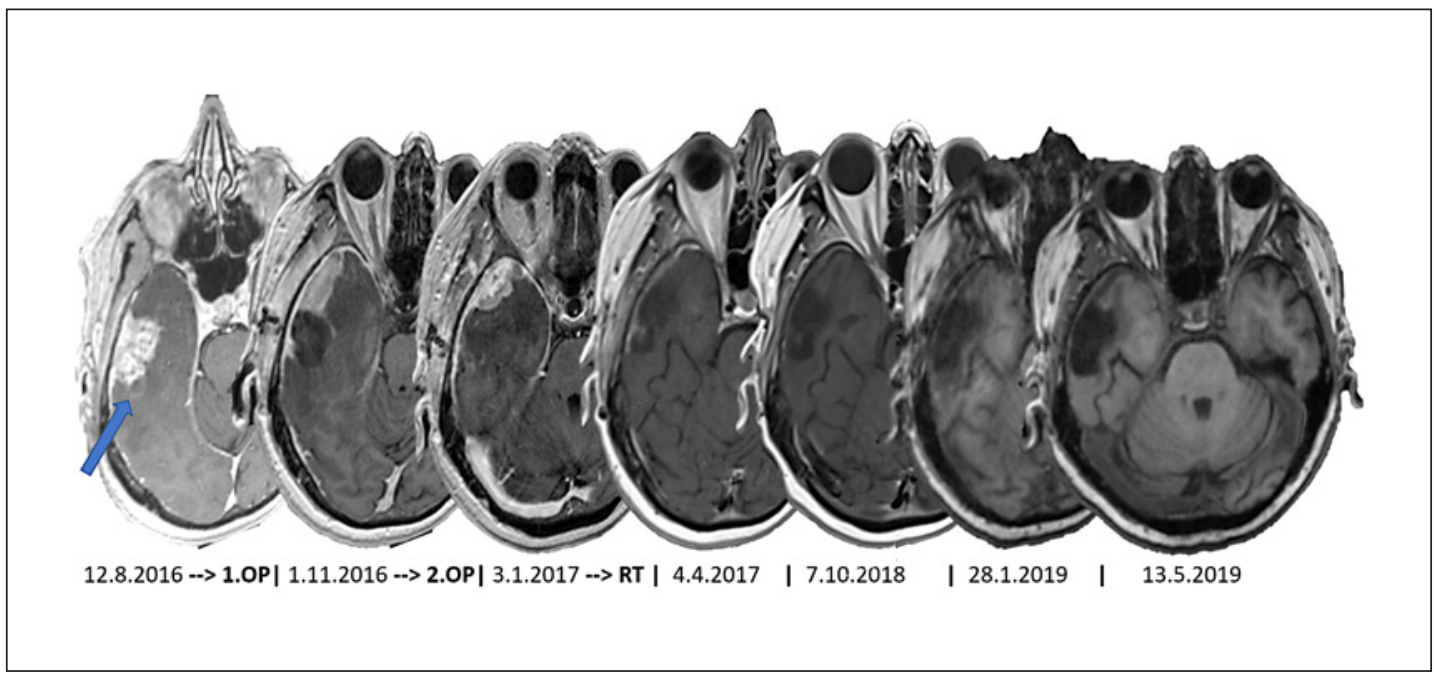

Fig. 1. Magnetic resonance images of the patient's brain in the course of the disease, with brain metastasis in the right temporal lobe (blue arrow). Dates are given in the format DMY.1.0P, first operation; 2.OP, second operation; RT, radiotherapy.

immunotherapy [3, 4]. However, local treatments including neurosurgery and radiotherapy (RT) remain the mainstay in comprehensive care [5]. Surgical removal is always individually indicated for patients with surgically accessible metastasis, depending, among other things, on its anatomic location.

With the development and greater availability of modern RT methods, a paradigm change in postoperative strategy is to be witnessed. Compared to the simple RT technique widely used in earlier times (i.e., whole brain RT [WBRT]), it is now possible to offer patients a wide selection of irradiation procedures ranging from local RT methods (stereotactic radiosurgery and stereotactic fractionated RT in 3-5 fractions) to modified WBRT (with a simultaneous integrated boost or with hippocampus-avoiding WBRT, or both at the same time) [6].

RT prescription is always a compromise between local control (separately in the resection cavity and in distant brain regions) and toxicity (edema and cognitive function) [7]. In conclusion, local RT of the metastatic area or the tumor cavity after surgery is utilized more and more often, following the results of large randomized studies evaluating quality of life and cognitive function apart from local control and overall survival [8-10].

\section{Case Report}

A 67-year-old female patient without serious intercurrences underwent surgery for grade 2 invasive endometrial uterine carcinoma. After adjuvant brachytherapy, the patient was regularly followed up. Twenty-three months after the primary surgery, she developed vertigo and temporary left-sided hemiparesis. Brain MRI showed a solitary lesion in the right temporal lobe (Fig. 1). Considering its favorable location, the patient's good general condition, and the absence of extracranial illness, the patient was indicated for neurosurgery and underwent radical resection without any sign of residual tumor on the postoperative CT scan. Histology confirmed metastasis of the adenocarcinoma. Adjuvant RT was not indicated, and observation by control MRI 3 months after surgery was recommended. This MRI, performed 2.5 months after the surgery, unfortunately showed early local recurrence with an enhancing 

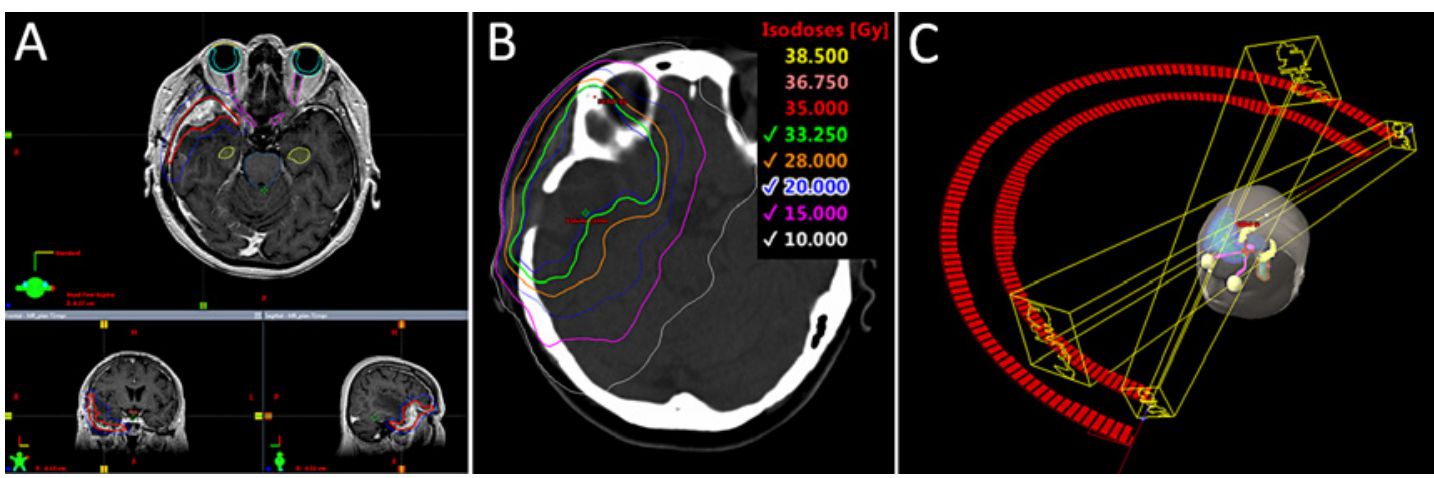

Fig. 2. Illustration of the radiotherapy planning process. A Contouring of the target volumes. The red curve represents the clinical target volume, and the blue curve the planning target volume. $\mathbf{B}$ Isodoses of the final irradiation plan. C Layout of the irradiation fields (volumetric modulated arc technique).

lesion localized ventral from the resection cavity and widely touching the dura with perifocal edema (Fig. 1).

Considering the patient's continuing good general condition, confirmed absence of extracranial disease, and operability of the newly discovered recurrence, the patient was indicated for a second resection, which resulted in a subtotal resection limited mostly in areas infiltrating the dura mater. Histology verified metastasis of a partly necrotic tumor of a similar appearance to that in the previous resection.

The patient was indicated for postoperative RT, and planning of RT started exactly 1 month after the operation, when the patient underwent planning MRI. Unfortunately, there was further progression of the tumor on this MRI, with distinct propagation along the adjacent meninges, especially more rostrally. No third operation was planned anymore, and the patient, with rapidly progressing metastasis, was indicated for palliative RT. Considering the character of the primary disease, the absence of extracranial metastases, and the locally aggressive behavior of the known macroscopic brain metastasis (together with the absence of further intracranial lesions), the patient was indicated for local RT and not for WBRT, despite meningeal impairment. The aim was also to reduce the RT dose to radiosensitive neurons in the hippocampal regions as much as reasonably achievable.

The target volumes and critical organs (including both hippocampi) were contoured in the RT planning system Eclipse ${ }^{\mathrm{TM}}$ version 11.03 (Varian Medical Systems, Palo Alto, CA, USA). During the construction of the clinical target volume (CTV; the region of known or suspected macroscopic and microscopic disease), the emphasis was put on a sufficient coverage of the area of contrast-enhancing adjacent meninges. An isocentric margin of $3 \mathrm{~mm}$ was added to the CTV, leading to the planning target volume (PTV; generally speaking, it is an additional margin to accommodate for all potential causes of uncertainty, such as interindividual variability in target volume definition, inaccuracies in image coregistration, movements of patients during RT, etc.) (Fig. 2). To ensure a stabile and reproducible position of the patient, an individually prepared thermoplastic fixation mask was used, as well as daily on-board verification imaging in the irradiation treatment room (image-guided RT-IGRT) via cone beam CT equipment with the possibility of subsequent online correction of the patient's position using a table with 6 degrees of freedom. Due to the size, shape, location, and spatial orientation of the PTV, and considering the previous progression of the disease, a dosage of $10 \times 3.5$ Gy was prescribed to the PTV. The patient was irradiated on a Varian TrueBeam STx linear accelerator (Varian Medical Systems) utilizing the volume-modulated RT technique 
Table 1. Two main current phase III studies dealing with the postoperative management of brain metastasis

\begin{tabular}{|c|c|c|c|c|c|c|c|c|c|}
\hline $\begin{array}{l}\text { Study [Ref.], } \\
\text { year }\end{array}$ & Cohort & $\begin{array}{l}\text { Patients, } \\
n\end{array}$ & $\begin{array}{l}\text { RT dose, } \\
\text { Gy }\end{array}$ & $\begin{array}{l}\text { mOS, } \\
\text { months }\end{array}$ & $\begin{array}{l}12 \text { months } \\
\text { of FFLR, \% }\end{array}$ & $\begin{array}{l}12 \text { months of } \\
\text { intracranial } \\
\text { control, } \%\end{array}$ & $\begin{array}{l}\text { Median time to } \\
\text { any intracranial } \\
\text { progression, } \\
\text { months }\end{array}$ & $\begin{array}{l}\text { Median survival } \\
\text { without any } \\
\text { cognitive } \\
\text { deterioration, } \\
\text { months }\end{array}$ & $\begin{array}{l}6 \text {-month } \\
\text { cognitive } \\
\text { deterioration, } \\
\%\end{array}$ \\
\hline \multirow{2}{*}{$\begin{array}{l}\text { Brown et al. } \\
{[8], 2017}\end{array}$} & SRS & 98 & $12-20$ & 11.6 & 60 & 37 & 6.4 & 3.7 & 52 \\
\hline & WBRT & 96 & $30-37.5$ & 12.2 & 80 & 72 & 27.5 & 3 & 85 \\
\hline $\begin{array}{l}\text { Study [Ref.], } \\
\text { year }\end{array}$ & Cohort & $\begin{array}{l}\text { Patients, } \\
n\end{array}$ & $\begin{array}{l}\text { RT dose, } \\
\text { Gy }\end{array}$ & $\begin{array}{l}\text { mOS, } \\
\text { months }\end{array}$ & $\begin{array}{l}12 \text { months } \\
\text { of FFLR, \% }\end{array}$ & $\begin{array}{l}\text { Recurrence in the } \\
\text { distal brain at } 12 \\
\text { months, } \%\end{array}$ & $\begin{array}{l}\text { Median time } \\
\text { without WBRT, } \\
\text { months }\end{array}$ & & \\
\hline \multirow{2}{*}{$\begin{array}{l}\text { Mahajan et } \\
\text { al. [9], } 2017\end{array}$} & SRS & 64 & $12-16$ & 17 & 72 & 42 & 16 & & \\
\hline & Observation & 68 & 0 & 18 & 43 & 33 & 15 & & \\
\hline
\end{tabular}

SRS, stereotactic radiosurgery; WBRT, whole brain radiotherapy; RT, radiotherapy; mOS, median overall survival; FFLR, freedom from local recurrence.

delivered by 2 coplanar $\left(209^{\circ}\right)$ 6-MV arcs (Fig. 2). In the course of RT, the patient was given corticoids for prophylactic purposes with sequential tapering after the end of RT.

The first postirradiation MRI (performed 2.5 months after RT) showed a regressing tumor with a remaining contrast-enhancing area in the adjacent dura, which continued to regress on the subsequent control MRI after another 2.5 months. Currently, the patient is 2.5 years after the end of RT, and only some posttreatment changes were described in the area of the right temporal lobe, without any intracranial enhancing lesions according to the last MRI scan.

\section{Discussion}

This case report presents a patient with aggressive brain metastasis of an endometrial uterine adenocarcinoma who had repeated early local relapses after 2 metastasectomies. The management of patients after brain metastasis operation has been reassessed in 2017. The randomized multicenter study NCCTG N107C/CEC.3 compared postoperative stereotactic radiosurgery with postoperative WBRT in a total of 194 patients [8]. In both cohorts, the patients with radioresistant and radiosensitive tumors were equally distributed. The co-primary outcomes were overall survival and survival without any deterioration of cognitive functions. With comparable overall survival, targeted stereotactic RT led to better results in terms of cognitive functional preservation (6-month deterioration in $85 \%$ of the cases after WBRT vs. $52 \%$ after local RT). In contrast, the patients in the WBRT cohort had better local and distal disease control. The long-term survivors at the evaluation 1 year after surgery significantly more frequently had cognitive deterioration after WBRT (24/27 patients; 89\%) than after radiosurgery (10/27 patients; $37 \%)$ [8].

The second study randomized 132 patients after surgery for 1-3 brain metastases to postoperation stereotactic radiosurgery versus postoperative observation [9]. The primary outcome was the time to local relapse defined as the occurrence of a new enhancing lesion in the cavity. Postoperative RT did not result in better overall survival or in a reduction in the possibility to die from neurological causes. However, 12-month freedom from local recur- 
rence was improved with RT (HR 0.46 [95\% CI 0.24-0.88]; $p=0.015$ ). The study (a singleinstitution study from the prestigious MD Anderson Cancer Center in Houston, TX, USA) confirmed that even with the employment of state-of-the-art surgical procedures, local control is insufficient. Together with a previously discussed study [8], it defines new guidelines for proceeding after metastasectomy, providing an indication for postoperative targeted RT to the area of the tumor cavity after surgery. Table 1 summarizes the data from the cited studies.

The case report presented in this article further supports the data published in the abovementioned studies. This case also illustrates an individualized approach to the planning of palliative RT in terms of target volume definition and dose prescription. This patient's target volumes were defined in close cooperation with a neurosurgeon, which is the preferred workflow in all cases with postoperative RT of the tumor cavity after metastasectomy. Especially in the case of subtotal resection with meningeal impairment as in this case report, the neurosurgeon can help significantly with appropriate contouring of the CTV. The important factor when deciding on an RT strategy for this concrete patient was the fact that the further prognosis fully depended on local control of the rapidly growing macrometastasis. Its control was given priority over control of the eventual microscopic brain disease, which would have urged us to indicate the patient for WBRT. Due to the size of the target volume and the patient's good overall condition, fractionated RT (in both studies mentioned above, single-fraction radiosurgery was performed) in 10 fractions was prescribed, but with an individual boost of the daily dose to $3.5 \mathrm{~Gy}$.

Patients, especially those assumed to survive longer (generally the group of patients in a better general condition, because they were able to cope with the surgery), need to be informed about the non-zero risk of worsening cognitive functions and quality of life with targeted RT, since that is how RT is often presented, of course in relation to WBRT. In the study discussed above (radiosurgery vs. WBRT), the incidence of 6-month cognitive functional deterioration among patients after radiosurgery was $52 \%$, which cannot be accounted for by any eventual salvage WBRT (20 out of 98 patients all together underwent salvage WBRT, and 13 of them had had cognitive deterioration even before salvage WBRT) [8]. Cognitive function and quality of life represent complex phenomena jointly determined by many factors related to patients, their family, their tumor, and their previous treatment. The type of RT is only one variable. General deterioration in performance status and cognition in any given patient can occur even without WBRT.

To conclude, nowadays there is no place for the nihilism that has in the past sometimes been seen among patients with brain metastases, and individualized therapy can provide patients with distinct benefits, as was the case with the present patient, who is now 2.5 years after treatment for an obviously very aggressive brain metastasis (repeated quick progression with meningeal impairment within months), which means exactly 2.5 years without any risk of the known side effects linked to WBRT. Aggressive local treatment of this patient has led to much better overall survival - at least in comparison to the median overall survival of 3.1 months among the unselected group mentioned in the introduction of this case report.

\section{Statement of Ethics}

The patient has consented to the submission of the case report to the journal. 
Fadrus et al.: Postsurgery Radiotherapy for Aggressive Brain Metastasis

\section{Disclosure Statement}

The authors have no conflicts of interest to disclose.

\section{Funding Sources}

This work was supported in part by the Ministry of Health, Czech Republic - Conceptual Development of Research Organization (MMCI 00209805), as well as by Ministry of Health, Czech Republic, grants AZV 18-00469A and 18-00398A.

\section{Author Contributions}

P.F. and T.K. wrote and prepared the first draft of the manuscript; P.D. and T.P. prepared and verified the RT treatment plan; T.K., P.P., L.H., J.Z., R.D., and R.B. participated in the diagnosis and treatment; I.K. participated in preparation of the manuscript, the literature search, and table and figure preparation; P.S. provided the concept and critically revised the manuscript. All authors read, revised, and approved the final manuscript.

\section{References}

1 Achrol AS, Rennert RC, Anders C, Soffietti R, Ahluwalia MS, Nayak L, et al. Brain metastases. Nat Rev Dis Primers. 2019;5(1):5.

2 Kazda T, Kuklova A, Pospisil P, Burkoň P, Slavík M, Hynková L, et al. Utilization of prognostic indexes for patients with brain metastases in daily radiotherapy routine - is the complexity and intricacy still an issue? Klin Onkol. 2015;28(5):352-8.

3 Chukwueke UN, Brastianos PK. Precision medical approaches to the diagnoses and management of brain metastases. Curr Treat Options Oncol. 2019;6;20(6):49.

4 Tawbi HA, Forsyth PA, Algazi A, Hamid O, Hodi FS, Moschos SJ, et al. Combined nivolumab and ipilimumab in melanoma metastatic to the brain. N Engl J Med. 2018;379(8):722-30.

5 Nahed BV, Alvarez-Breckenridge C, Brastianos PK, Shih H, Sloan A, Ammirati M, et al. Congress of Neurological Surgeons systematic review and evidence-based guidelines on the role of surgery in the management of adults with metastatic brain tumors. Neurosurgery. 2019;84(3):E152-E155.

6 Kazda T, Jancalek R, Pospisil P, Sevela O, Prochazka T, Vrzal M, et al. Why and how to spare the hippocampus during brain radiotherapy: the developing role of hippocampal avoidance in cranial radiotherapy. Radiat Oncol. 2014;9:139.

7 Lakomy R, Hynkova L, Pospisil P, Burkon P, Slavik M, Slampa P, et al. Patterns of failure after brain metastases radiotherapy: reflections on the importance for treatment and clinical trials reporting. Neoplasma. 2017;64(3):329-37.

8 Brown PD, Ballman KV, Cerhan JH, Anderson SK, Carrero XW, Whitton AC, et al. Postoperative stereotactic radiosurgery compared with whole brain radiotherapy for resected metastatic brain disease (NCCTG N107C/ CEC·3): a multicentre, randomised, controlled, phase 3 trial. Lancet Oncol. 2017;18(8):1049-60.

9 Mahajan A, Ahmed S, McAleer MF, Weinberg JS, Li J, Brown P, et al. Post-operative stereotactic radiosurgery versus observation for completely resected brain metastases: a single-centre, randomised, controlled, phase 3 trial. Lancet Oncol. 2017;18(8):1040-8.

10 Traylor JI, Habib A, Patel R, Muir M, Gadot R, Briere T, et al. Fractionated stereotactic radiotherapy for local control of resected brain metastases. J Neurooncol. 2019;144(2):343-50. 